\title{
Targeting Zinc Protoporphyrin Liposomes to the Spleen Using Reticuloendothelial Blockade with Blank Liposomes
}

\author{
CHARLES J. HAMORI, DANILO D. LASIC, HENDRIK J. VREMAN, AND DAVID K. STEVENSON \\ University of California, San Diego, School of Medicine, La Jolla, California 92037 [C.J.H.]; Liposome \\ Technology, Inc., Menlo Park, California 94025 [D.D.L.]; and Department of Pediatrics, Stanford University \\ School of Medicine, Stanford, California 94305 [H.J.V., D.K.S.]
}

\begin{abstract}
Metalloporphyrin inhibitors of heme oxygenase have been studied for use in the prevention of hyperbilirubinemia of the neonate. One report has suggested that incorporation of these drugs into liposomes can increase their localization to the spleen, dramatically reducing heme oxygenase activity in that important hemedegrading organ. We sought to further increase porphyrin delivery to the spleen by using reticuloendothelial blockade with blank liposomes $2 \mathrm{~h}$ before injection of $0.3 \mu \mathrm{m}$ extruded zinc protoporphyrin liposomes (L-ZnPP). Control adult rats without hemolysis had splenic heme oxygenase activity of $1.07 \pm 0.09 \mathrm{nmol}$ carbon monoxide $(\mathrm{CO}) / \mathrm{h} / \mathrm{mg}$ protein. Rats treated with $\mathrm{L}-\mathrm{ZnPP}$ alone had splenic heme oxygenase activity of $0.53 \pm 0.16 \mathrm{nmol} \mathrm{CO} / \mathrm{h} / \mathrm{mg}$ protein $6 \mathrm{~h}$ after L-ZnPP dosing. However, rats treated with 1000 $\mu \mathrm{mol}$ of blank liposomes per $\mathrm{kg}$ to saturate the reticuloendothelial system $2 \mathrm{~h}$ before $\mathrm{L}-\mathrm{ZnPP}$ administration had splenic heme oxygenase activity of $0.25 \pm 0.16 \mathrm{nmol} \mathrm{CO} /$ $\mathrm{h} / \mathrm{mg}$ protein at $\mathrm{t}=6 \mathrm{~h}$, which is significantly less than that of the L-ZnPP alone group $(p<0.05)$. In adult rats treated with heat-damaged red blood cells (RBC) to simulate hemolysis, treatment with $10 \mu \mathrm{mol}$ of aqueous $\mathrm{ZnPP}$ per $\mathrm{kg}$ or $10 \mu \mathrm{mol}$ of untargeted L-ZnPP per $\mathrm{kg}$ did not produce a difference from control in total body bilirubin production as estimated by $\mathrm{CO}$ excretion. However, RBCtreated rats given $1000 \mu \mathrm{mol}$ of blank liposomes per $\mathrm{kg} 2$ $h$ before $L-Z n P P$ administration produced significantly less $\mathrm{CO}$ than control, aqueous $\mathrm{ZnPP}$-treated, and untargeted $\mathrm{L}-\mathrm{ZnPP}$-treated rats from 8 to $12 \mathrm{~h}$ after RBC treatment. In addition, splenic heme oxygenase activity in RBCtreated rats receiving $10 \mu \mathrm{mol}$ of targeted $\mathrm{L}-\mathrm{ZnPP}$ per $\mathrm{kg}$ was completely eliminated $12 \mathrm{~h}$ after RBC treatment. These results indicate that targeting of $\mathrm{L}-\mathrm{ZnPP}$ to the spleen with reticuloendothelial blockade leads to improved in vivo suppression of total body bilirubin production in adult rats treated with heat-damaged RBC. More complete inhibition of splenic heme oxygenase is the likely mechanism for this improved therapeutic effect. (Pediatr Res 34: $1-5,1993$ )
\end{abstract}

\section{Abbreviations}

ZnPP, zinc protoporphyrin

L-ZnPP, liposomal zinc protoporphyrin

$\mathrm{SnPP}$, tin protoporphyrin

HO, heme oxygenase

Received November 23, 1992; accepted February 26, 1993.

Correspondence: David K. Stevenson, M.D., Department of Pediatrics, Division of Neonatology, Stanford University Medical Center, Stanford, CA 94305.

Supported by grants from the Weiss Foundation, USPHS, NIH Grant HD14426, the Mead Johnson Nutritional Division, and the Christopher Taylor Harrison Research Fund.

\author{
CO, carbon monoxide \\ VeCO, total body carbon monoxide excretion \\ RES, reticuloendothelial system \\ RBC, red blood cell \\ EPC, egg phosphatidylcholine \\ EPG, egg phosphatidylglycerol \\ i.p., intraperitoneal(ly)
}

Neonatal hyperbilirubinemia continues to be a common concern, with more than $6 \%$ of newborns developing significant jaundice (serum bilirubin above $220 \mu \mathrm{mol} / \mathrm{L}$ ) nationwide (1). Bilirubin is produced from heme by a two-step pathway of which $\mathrm{HO}$ (EC 1.14.99.3) is the rate-limiting enzyme (2). In the neonate, bilirubin produced in the RES from senescent fetal RBC cannot be excreted by the immature conjugating mechanisms of the neonatal liver, leading to blood bilirubin levels far above those of normal adults. Severe neonatal hyperbilirubinemia is associated with kernicterus and death, although the pathophysiology of this process is still being studied and debated (3-6). Current treatments for neonatal jaundice, such as phototherapy, focus on increasing the clearance of bilirubin from the blood. An experimental treatment for neonatal jaundice is being investigated that would use analogs of heme to competitively inhibit $\mathrm{HO}(7,8)$. This approach is attractive because elevated bilirubin levels can be prevented.

A variety of metalloporphyrin $\mathrm{HO}$ inhibitors have been studied in several animal models (7-11). The first trial of SnPP in human neonates (12), however, was clinically unremarkable (13). Perhaps this was because insufficient amounts of metalloporphyrin were available to heme-degrading tissues of the RES at the low doses of 1-2 $\mu \mathrm{mol} \mathrm{SnPP}$ per $\mathrm{kg}$ used in that study. One obvious way to increase the drug localized to the RES would be to increase the dose. However, this might lead to an increase in adverse reactions as well. Liposomal incorporation may make it possible to increase the amount of porphyrin localized to the RES without dose escalation.

Liposomes are artificial lipid vesicles with one or more concentric bilayers composed mainly of phospholipid and cholesterol. They can be used to encapsulate drugs in the aqueous volume, the lipid bilayer itself, or a combination of both (14). Their usefulness for the delivery of many drugs has been limited because most liposomes are quickly scavenged by RES (15). Landaw et al. (16) incorporated SnPP into unsized multilamellar vesicles of EPC and demonstrated increased localization of SnPP to the spleen as compared with SnPP administered in the aqueous form, with a concomitant decrease in splenic HO activity. In addition, they showed decreased biliary bilirubin output in bile duct-cannulated rats treated with liposomal tin mesoporphyrin. 
Although liposomes are cleared from the blood by the RES, they actually accumulate poorly in the spleen relative to the liver in most circumstances. In general, more than $50 \%$ of an injected liposome dose will be taken up by the liver (Kupffer's cells), with only $10 \%$ going to the spleen (17). Targeting strategies can be used to increase the liposome dose delivered to the spleen. Our goals in the present study were: $l$ ) to formulate and characterize a stable preparation of $\mathrm{L}-\mathrm{ZnPP} ; 2$ ) to assess whether $\mathrm{L}-\mathrm{ZnPP}$ could be targeted effectively to the spleen using reticuloendothelial blockade; and 3) to study in adult rats with and without hemolysis the therapeutic efficacy of targeted versus nontargeted $\mathrm{L}-\mathrm{ZnPP}$, as reflected by suppression of $\mathrm{VeCO}$.

\section{MATERIALS AND METHODS}

Animals. Our animal use protocol was approved by the Stanford University Division of Laboratory Animal Medicine. Adult male Wistar rats (Simonsen Laboratories, Inc., Gilroy, CA) weighing 275 to $325 \mathrm{~g}$ were used. They were housed at $25 \pm 1{ }^{\circ} \mathrm{C}$, with a 12-h light cycle starting at $0700 \mathrm{~h}$, and maintained on a diet of Wayne MRH 22/5 Rodent Blox (Continental Grain Co., Chicago, IL) and unlimited water. They were fasted for $12 \mathrm{~h}$ before experimentation. Once experimentation was begun, they were kept in subdued light.

Liposomes. EPC and EPG were purchased from Avanti Polar Lipids, Birmingham, AL. Cholesterol was obtained from Sigma Chemical Co., St. Louis, MO. ZnPP was from Porphyrin Products, Inc., Logan, UT. All chemicals used were of reagent grade or better. Initial encapsulation studies of ZnPP were done using the ethanol injection method (18). Briefly, lipid and porphyrin powders were dissolved in ethanol to a volume of $10 \%$ of the final desired volume. This mixture was then injected slowly into vigorously stirred $100 \mathrm{mM}$ potassium phosphate buffer, $\mathrm{pH} 7.4$, to form liposomes. Although this method allowed us to study the bilayer binding characteristics of the porphyrin, we encountered difficulties with size stability that were likely due to inadequate solvent removal by dialysis. Thus, for animal studies, $\mathrm{ZnPP}$ liposomes were made by the thin film method (19). The total lipid concentration was $50 \mathrm{mM}$. EPC and EPG in a 4:1 molar ratio were dissolved in chloroform and evaporated to a thin film under vacuum on a rotary evaporator. The dry film was additionally placed at a vacuum of 5 mtorr for at least $12 \mathrm{~h}$ to remove residual solvent. $\mathrm{ZnPP}$ was made into a $3.2 \mathrm{mM}$ solution by dissolving $20.0 \mathrm{mg}$ of the powder into $500 \mu \mathrm{L} 10 \%$ (vol/vol) ethanolamine with stirring. The volume was brought to $7.5 \mathrm{~mL}$ with distilled water, and $1.0 \mathrm{~mL}$ of $1 \mathrm{M}$ potassium phosphate buffer, $\mathrm{pH} 7.4$, was added. The $\mathrm{pH}$ was titrated to 7.4 with $1 \mathrm{M}$ $\mathrm{HCl}$, and the final volume was brought to $10.0 \mathrm{~mL}$ with distilled water. The $\mathrm{ZnPP}$ solution was added to the dry lipid film and the mixture placed on a wrist shaker for $30 \mathrm{~min}$. The resultant liposomes were sequentially extruded under nitrogen pressure three times through two stacked $0.4-\mu \mathrm{m}$ polycarbonate filters (Nucleopore Corp., Pleasanton, CA) held in a commercially available extrusion cell (Lipex, Vancouver, Canada). The mean particle size was approximately $0.3 \mu \mathrm{m}$ as measured with a Coulter submicron particle sizer (Coulter Electronics, Inc., Hialeah, FL). In the phase contrast optical microscope, the tail (diameter $\geq 0.5 \mu \mathrm{m}$ ) of the size distribution could be observed. No large liposomes or aggregates were seen. The fluorescence mode showed a uniform glow indicating homogeneous incorporation of the porphyrin molecules into the liposomes. Blank liposomes for saturation of the RES were made to a concentration of $100 \mathrm{mM}$ total lipid from EPC:EPG:cholesterol (1:1:1) by the same method with hydration with normal saline. Blank liposomes were also extruded to a size of $0.3 \mu \mathrm{m}$. The liposomes were stored for up to $1 \mathrm{wk}$ at $4-8^{\circ} \mathrm{C}$. The size distribution and drug concentration did not change over this time period.

ZnPP assay. Liposomes were assayed for ZnPP concentration spectrofluorimetrically using $90 \%$ ethanol/10\% $1 \mathrm{M} \mathrm{HCl}$ (vol/ vol) as a solvent. The emission at $603 \mathrm{~nm}$ with excitation at 407 $\mathrm{nm}$ was read and compared with a standard curve.

Octanol/water partition coefficient. A small amount of aqueous $\mathrm{ZnPP}$ was diluted with water to $1.0 \mathrm{~mL}$ total volume. One $\mathrm{mL}$ of 1-octanol was added, followed by vigorous mixing for at least $1 \mathrm{~min}$. The phases were separated by centrifugation at $3000 \times g$ for $15 \mathrm{~min}$. The amount of $\mathrm{ZnPP}$ in each phase was quantitated, with the partition coefficient being the amount of drug in octanol divided by the amount in water.

Encapsulation efficiency. The percentage of drug encapsulated was determined by suspending $100 \mu \mathrm{L}$ of liposomes in $900 \mu \mathrm{L}$ of saline in a microfuge tube and spinning at $15000 \times g$ for 15 min. The amount of $\mathrm{ZnPP}$ in the pellet and supernatant was determined as above with encapsulation efficiency defined as the amount of drug recovered in the pellet divided by the total drug. For liposomes used in animals, this value was uniformly above $90 \%$.

Plasma induced leak assay. Thin film L-ZnPP preparations were assayed for leakage in human plasma. The sample was diluted 10-fold in normal saline and mixed 1:1 with pooled human plasma. The mixture was incubated for $1 \mathrm{~h}$ at $37^{\circ} \mathrm{C}$, then separated on a $20-\mathrm{cm}$ Bio-Gel A15 M column (Biorad Laboratories, Richmond, CA) eluted with degassed normal saline. Fractions of $0.5 \mathrm{~mL}$ were collected and assayed for $\mathrm{ZnPP}$ concentration. Encapsulation efficiency was defined as the ratio of the first peak (liposomes) to the total recovered drug. For these thin film preparations, 40 to $50 \%$ of the drug was found to leak out in 1 h.

Hemin solution. Hemin for simulation of hemolysis was made into a $6 \mathrm{mM}$ solution similar to $\mathrm{ZnPP}$. Thirty $\mu \mathrm{mol}$ hemin per $\mathrm{kg}$ body weight were injected by the i.p. route.

Damaged $R B C$. Fresh blood from two donor rats was collected by cardiac puncture into acid citrate dextrose. The RBC were isolated by centifugation at $3000 \times g$ for $15 \mathrm{~min}$, and incubated at $49.5 \pm 0.5^{\circ} \mathrm{C}$ for $20 \mathrm{~min}(20)$. The cells were washed twice with 1.5 volumes of normal saline and resuspended in one volume of normal saline for injection of $1.5 \mathrm{~mL}$ via the tail vein. The total $\mathrm{Hb}$ was measured by the cyanmethemoglobin procedure (Bulletin 525, Sigma Chemical Co.). The amount of heme injected was approximately $30 \mu \mathrm{mol} / \mathrm{kg}$ body weight.

$V e C O$. The in vivo total body bilirubin production was estimated using measurements of the VeCO. This technique has been described in detail elsewhere $(10,11)$.

$\mathrm{HO}$ assay. The $\mathrm{HO}$ activity of supernatant fractions of homogenized liver and spleen centrifuged at $15000 \times \mathrm{g}$ for $15 \mathrm{~min}$ was determined using a gas chromatographic assay described previously $(10,11,21)$.

Experimental procedure. Our targeting method was first assessed in adult rats without hemolysis. An initial VeCO was determined. Control animals received either an RES saturating dose of $1000 \mu \mathrm{mol}$ total lipid per kg i.p. as blank liposomes or an equal volume of saline i.p. followed $2 \mathrm{~h}$ later by an i.p. dose of blank liposomes equal to $150 \mu \mathrm{mol}$ total lipid per $\mathrm{kg}$. Experimental animals were given either an RES saturating dose of blank liposomes or an equal volume of saline, followed $2 \mathrm{~h}$ later by $10 \mu \mathrm{mol} \mathrm{L-ZnPP}$ per $\mathrm{kg}$. Six h after L-ZnPP treatment, the animals were again assayed for $\mathrm{VeCO}$, killed, and the livers and spleens were assayed for $\mathrm{HO}$ activity.

The assessment of L-ZnPP in a hemolytic model was done by two methods: first, using an i.p. dose of hemin solution; second, using an i.v. dose of heat-damaged RBC. Both sets of experiments were done using essentially the same protocol. An initial $\mathrm{VeCO}$ was determined at $\mathrm{t}=0 \mathrm{~h}$. A dose of $30 \mu \mathrm{mol}$ hemin per $\mathrm{kg}$ $(\sim 1.5 \mathrm{~mL}$ i.p.) or approximately $30 \mu \mathrm{mol} \mathrm{RBC}$ heme per $\mathrm{kg}(1.5$ $\mathrm{mL}$ i.v.) was administered to each animal. At this time, animals also received either an i.p. injection of saline or an i.p. dose of $1000 \mu \mathrm{mol}$ total lipid per $\mathrm{kg}$ as blank liposomes to saturate the RES. At $t=2 \mathrm{~h}$, the VeCO was again measured, after which the animals were given an i.p. dose of $10 \mu \mathrm{mol} \mathrm{L}-\mathrm{ZnPP}$ per $\mathrm{kg}$, an equal volume of blank liposomes, or $10 \mu \mathrm{mol}$ aqueous $\mathrm{ZnPP}$ per 
kg. Bihourly $\mathrm{VeCO}$ readings were then performed until $\mathrm{CO}$ excretion returned to near baseline levels. Animals that had been given damaged $\mathrm{RBC}$ were killed at $\mathrm{t}=12 \mathrm{~h}$ and assayed for $\mathrm{HO}$ activity in the liver and spleen.

Statistics. The data are expressed as a mean $\pm \mathrm{SD}$; the number of determinations is given in parentheses. Data were analyzed using a one-way analysis of variance. Statistical differences between groups were determined using the Scheffe F-test.

\section{RESULTS}

Table 1 shows the encapsulation of $\mathrm{ZnPP}$ into liposomes by the ethanol injection method. The optimum encapsulated drug to lipid ratio was about $1: 16$, allowing greater than $90 \%$ of the drug to be encapsulated with no need for free drug removal. The octanol:water partition coefficient of $\mathrm{ZnPP}$ was found to be 3.2 \pm 0.2 (not shown), which indicates that most of the encapsulated $\mathrm{ZnPP}$ is located in the bilayer of the liposomes (17).

The effect of targeting ZnPP liposomes to the spleen of adult rats without hemolysis is shown in Table 2 . The $\mathrm{HO}$ activity in the spleens and livers of both L-ZnPP-treated groups was significantly $(p<0.01)$ lower than that of the controls. In addition, the splenic $\mathrm{HO}$ activity in the rats receiving a predose of blank liposomes to saturate the RES was significantly $(p<0.05)$ lower than that of animals who had received a predose of saline before administration of L-ZnPP. Six h after L-ZnPP administration, the $\mathrm{VeCO}$ of the saline-pretreated group had dropped to $79 \%$ of its initial value, and the $\mathrm{VeCO}$ of the liposome-pretreated group had dropped to $72 \%$ of its initial value. The VeCO of the control group did not change over this time period. The difference in $\mathrm{VeCO}$ between the two L-ZnPP-treated groups and the control group was significant at $p<0.01$.

Figure $1 A$ shows the results of the $\mathrm{VeCO}$ readings of animals that had been treated with an i.p. dose of hemin to simulate hemolysis. An initial rise in the $\mathrm{VeCO}$ was seen in all animals. Administration of L-ZnPP at $\mathrm{t}=2 \mathrm{~h}$ blocked further rises in the $\mathrm{VeCO}$ over the next $10 \mathrm{~h}$. L-ZnPP-treated rats, pretreated with saline, produced significantly $(p<0.01)$ less $\mathrm{CO}$ than liposometreated controls at $\mathrm{t}=6$ and $\mathrm{t}=8 \mathrm{~h}$. L-ZnPP-treated rats pretreated with the blank liposomes produced significantly less $\mathrm{CO}$ than controls from $\mathrm{t}=4$ to $\mathrm{t}=8 \mathrm{~h}$. Aqueous $\mathrm{ZnPP}$ at a dose of $10 \mu \mathrm{mol} / \mathrm{kg}$ administered at $\mathrm{t}=2 \mathrm{~h}$ produced no statistical difference from control in this model. Both groups of animals dosed with L-ZnPP showed statistical difference $(p<0.01)$ from the aqueous $\mathrm{ZnPP}$-treated group, the saline-predosed group at $\mathrm{t}$ $=8 \mathrm{~h}$, and the liposome-predosed group a $\mathrm{t}=4,6$, and $8 \mathrm{~h}$. There was no statistical difference between L-ZnPP-treated rats predosed with saline, and those predosed with an RES saturating dose of blank liposomes over the course of this experiment.

Figure $1 B$ shows the results of $\mathrm{VeCO}$ determinations in animals treated with damaged $\mathrm{RBC}$ to simulate hemolysis. All rats given damaged $\mathrm{RBC}$ showed a rapid rise in the VeCO. Animals given a pretreatment of blank liposomes to saturate the RES $2 \mathrm{~h}$ before $\mathrm{L}-\mathrm{ZnPP}$ showed a more rapid decline in $\mathrm{VeCO}$ from $\mathrm{t}=$ 6 to $12 \mathrm{~h}$ than did control, aqueous ZnPP-treated, or salinepretreated L-ZnPP-treated animals. Lipid-pretreated animals produced significantly $(p<0.05)$ less $\mathrm{CO}$ at $\mathrm{t}=8,10$, and $12 \mathrm{~h}$ after RBC treatment compared with all other groups.
Table 3 shows the liver and spleen $\mathrm{HO}$ activity of the animals from Figure $1 B$ killed at $\mathrm{t}=12 \mathrm{~h}$. All ZnPP-treated groups had significantly decreased liver $\mathrm{HO}$ activity relative to controls. In addition, both L-ZnPP-treated groups had significantly decreased splenic HO activity relative to controls. In the lipid pretreated group, splenic $\mathrm{HO}$ activity was completely eliminated.

\section{DISCUSSION}

The encapsulation of porphyrins into liposomes is not a new idea. The work of Jori et al. with porphyrin liposomes for use in photodynamic destruction of tumors $(18,22,23)$ has been extensive. This article provides the second report of the use of porphyrins and liposomes toward the goal of preventing jaundice in neonates. We have shown that ZnPP can be incorporated into liposomes of EPC and EPG with good efficiency by both the ethanol injection and thin film methods. Our thin film preparations were easily extruded to $0.3 \mu \mathrm{m}$ without loss of drug or encapsulation efficiency. Because the negatively charged EPG was included in the bilayer, our liposomal suspension did not aggregate even after a week of storage, and our experience with other negatively charged preparations leads us to believe that this formulation could be stored much longer. Furthermore, when prepared with the proper cryoprotectant, we have found that similar preparations are easily lyophilized, increasing shelf-life dramatically. In contrast, neutral EPC preparations are in general quite unstable and would be expected to form uninjectable aggregates in a matter of days.

In adult rats without hemolysis, a dose of $10 \mu \mathrm{mol} \mathrm{L-ZnPP}$ per kg suppressed the $\mathrm{VeCO}$ and liver and spleen $\mathrm{HO}$ activity to a level comparable to that reached using an aqueous dose of 40 $\mu \mathrm{mol} \mathrm{ZnPP}$ per $\mathrm{kg}(10)$. Our results also indicate that reticuloendothelial blockade with blank liposomes $2 \mathrm{~h}$ before administration of L-ZnPP increases the degree to which splenic HO is inhibited. Interestingly, it was difficult to correlate this increased splenic HO inhibition with increased therapeutic efficacy as reflected by suppression of the VeCO.

We believe that, because bilirubin production in the adult rat without hemolysis is rather limited, this model was not sensitive enough for us to discern a true difference. Yet, the results also indicate that there was essentially no benefit seen due to targeting of $\mathrm{ZnPP}$ to the spleen in the inhibition of the $\mathrm{VeCO}$ of adult rats when i.p. hemin was given to simulate hemolysis. However, when damaged $\mathrm{RBC}$ were injected i.v. as a hemolytic challenge, the results were strikingly different. Liposomal ZnPP produced no difference from control unless a pretreatment of blank liposomes was given to saturate the RES. This raises the question of which of these two hemolytic models is more representative of jaundice in the neonate.

Serum albumin is a well-described carrier of endogenous porphyrins. Yet, few studies of the pharmacodynamics of injected exogenous porphyrins have been reported. The photosensitizer hematoporphyrin injected as an aqueous solution associates heavily with plasma lipoproteins, especially HDL, in which it can circulate for extended periods of time (23). Other evidence indicates that hemopexin would carry a substantial portion of SnPP injected as an aqueous solution (24). The degree of porphyrin association with lipoproteins and hemopexin is related to

Table 1. Encapsulation of ZnPP into ethanol injection liposomes of varying formulation*

\begin{tabular}{lccccc}
\hline Formulation & Molar ratio & $\begin{array}{c}{[\text { Lipid }]} \\
(\mu \mathrm{mol} / \mathrm{mL})\end{array}$ & $\begin{array}{c}{[\text { ZnPP] }} \\
(\mu \mathrm{mol} / \mathrm{mL})\end{array}$ & $\begin{array}{c}\text { Encapsulation } \\
\text { efficiency }(\%)\end{array}$ & $\begin{array}{c}\text { Drug:lipid } \\
(\mu \mathrm{mol} / \mu \mathrm{mol}) \dagger\end{array}$ \\
\hline EPC:Ch $(n=3)$ & $55: 45$ & 25 & 1.6 & $50 \pm 8$ & $1: 31$ \\
EPC:EPG:Ch $(n=3)$ & $45: 10: 45$ & 25 & 1.6 & $56 \pm 6$ & $1: 28$ \\
EPC $(n=3)$ & 100 & 25 & 1.6 & $95 \pm 4$ & $1: 16$ \\
EPC $(n=2)$ & 100 & 25 & 3.2 & 67 & $1: 12$ \\
EPC:EPG $(n=3)$ & $80: 20$ & 25 & 1.6 & $96 \pm 3$ & $1: 16$ \\
\hline
\end{tabular}

* [Lipid], lipid concentration; [ZnPP], ZnPP concentration; $\mathrm{Ch}$, cholesterol.

$\dagger$ This reflects the ratio of encapsulated drug to total lipid. Calculation is as follows: [ZnPP] $\times$ encapsulation efficiency/[Lipid]. 
Table 2. Effect of ZnPP liposomes on total body bilirubin production and tissue HO activity in adult rat*

\begin{tabular}{|c|c|c|c|c|}
\hline \multirow[b]{2}{*}{ Group } & \multicolumn{2}{|c|}{$\mathrm{HO}$ activity (nmol CO/h/mg protein) } & \multicolumn{2}{|c|}{$\mathrm{VeCO}(\mu \mathrm{L} \mathrm{CO} / \mathrm{kg} / \mathrm{h})$} \\
\hline & Spleen & Liver & $\mathrm{t}=0 \mathrm{~h}$ & $t=6 \mathrm{~h}$ \\
\hline Control $(n=4)$ & $1.07 \pm 0.09$ & $0.37 \pm 0.04$ & $19.1 \pm 1.6$ & $19.2 \pm 0.5$ \\
\hline Saline + L-ZnPP $(n=5)$ & $0.53 \pm 0.16 \dagger$ & $0.06 \pm 0.02 \dagger$ & $18.8 \pm 1.3$ & $14.8 \pm 2.0 \dagger$ \\
\hline Liposome + L-ZnPP $(n=5)$ & $0.25 \pm 0.16 \dagger \ddagger$ & $0.06 \pm 0.02 \dagger$ & $19.1 \pm 1.1$ & $13.8 \pm 1.1 \dagger$ \\
\hline
\end{tabular}

* An initial $\mathrm{VeCO}$ was determined and the animals were predosed with $1000 \mu \mathrm{mol}$ total lipid per $\mathrm{kg}$ as blank liposomes or saline as indicated. Two h later, animals were given $10 \mu \mathrm{mol} \mathrm{L-ZnPP}$ per $\mathrm{kg}$ or an equal volume of blank liposomes. Six $\mathrm{h}$ later, the VeCO was again measured, and the animals were killed and assayed for HO in the indicated tissues.

$\dagger p<0.01$ relative to controls, Scheffe F-test.

$\ddagger p<0.05$ relative to the saline-pretreated group, Scheffe F-test.

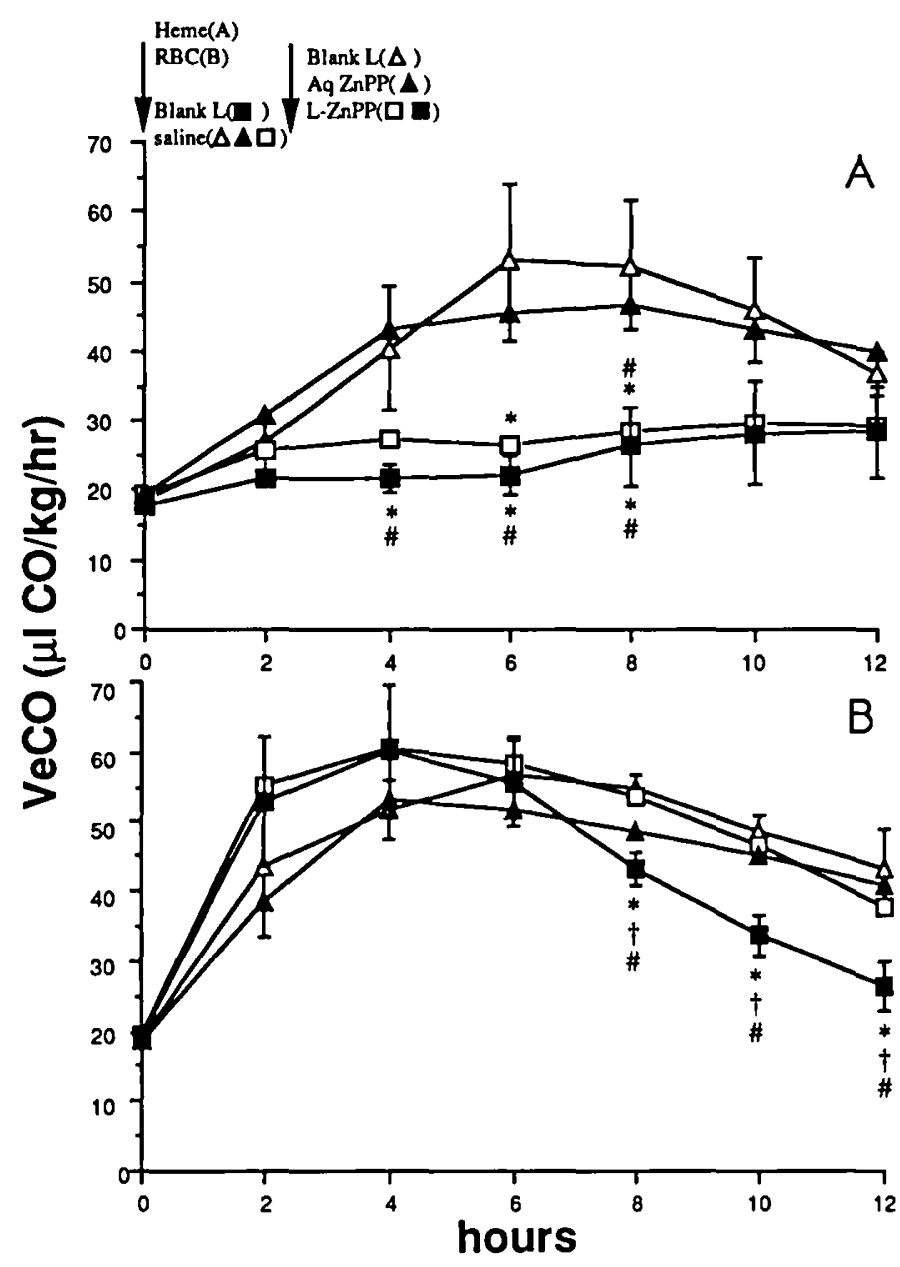

Fig. 1. CO production in adult rats with simulated hemolysis. An initial VeCO was determined at $\mathrm{t}=0 \mathrm{~h}$. All animals were then treated i.p. with either $30 \mu \mathrm{mol}$ hemin per $\mathrm{kg}$ body weight $(A)$ or i.v. with approximately $30 \mu \mathrm{mol}$ heme per $\mathrm{kg}$ in the form of heat-damaged RBC $(B)$. The two arrows above panel $A$ indicate what pretreatment and treatment, respectively, each group of animals, represented by the symbols, received at the indicated time point. At $t=0$, animals represented by were pretreated with $1000 \mu \mathrm{mol}$ total lipid per $\mathrm{kg}$ body weight as blank liposomes (Blank $L)$ per $\mathrm{kg}$ body weight $(n=4)$. Animals represented by $\Delta$ were given $10 \mu \mathrm{mol}$ aqueous $\mathrm{ZnPP}(A q \mathrm{ZnPP})$ per $\mathrm{kg}$ body weight $(n=4)$. Liposome encapsulated $\mathrm{ZnPP}(\mathrm{L}-\mathrm{ZnPP})$ was given to both the saline-pretreated $(n=3, \square)$ and the liposome-pretreated $(n=$ 3 ; ) animals. VeCO readings were continued until $t=12 \mathrm{~h}$. (* indicates $p<0.01$ compared with controls; $\dagger$ indicates $p<0.01$ compared with saline-pretreated L-ZnPP-treated group; \# indicates $p<0.05$ compared with aqueous $\mathrm{ZnPP}$ group).
Table 3. Heme oxygenase activity ( $\mathrm{nmol} \mathrm{CO} / \mathrm{h} / \mathrm{mg}$ protein) in tissues of adult rats from Figure $1 B$ killed at $t=12 h^{*}$

\begin{tabular}{lcc}
\multicolumn{1}{c}{ Group } & \multicolumn{1}{c}{ Spleen } & \multicolumn{1}{c}{ Liver } \\
\hline Control $(n=4)$ & $1.33 \pm 0.44$ & $0.31 \pm 0.05$ \\
Aqueous ZnPP $(n=4)$ & $0.73 \pm 0.20$ & $0.23 \pm 0.03 \dagger$ \\
Saline + L-ZnPP $(n=3)$ & $0.25 \pm 0.07 \dagger$ & $0.12 \pm 0.02 \dagger$ \\
Liposomes + L-ZnPP $(n=3)$ & ND $\ddagger$ & $0.09 \pm 0.02 \dagger \ddagger$ \\
\hline
\end{tabular}

* ND, none detected.

$\dagger p<0.01$ compared with control, Scheffe F-test.

$\ddagger p<0.01$ compared with aqueous $\mathrm{ZnPP}$ group, Scheffe F-test.

hydrophobicity $(23,24)$. Because hemin, like SnPP and hematoporphyrin, is hydrophobic, it likely would associate with plasma lipoproteins and hemopexin after injection and would be cleared from the circulation by the hepatocyte, not the RES macrophage. Thus, injection of aqueous hemin would preferentially stimulate liver, specifically hepatocyte, $\mathrm{HO}$ activity. In contrast, heat-damaged RBC are cleared from the circulation by the macrophages of the RES, particularly those in the spleen (20). A similar mechanism is responsible for clearing damaged $\mathrm{RBC}$ from the circulation of the neonate with hemolytic disease (1). Thus, injection of heat-damaged RBC into the rat is probably a better model for studying neonatal jaundice than injection of aqueous hemin. When we focus only on the results of the $\mathrm{VeCO}$ readings in animals treated with damaged $\mathrm{RBC}$, we see a clear benefit of targeting $\mathrm{ZnPP}$ to the spleen.

In general, we have demonstrated more complete inhibition of liver $\mathrm{HO}$ activity than of splenic $\mathrm{HO}$ activity in vivo with administration of aqueous $\mathrm{ZnPP}(10,11)$. As mentioned earlier, this is probably due to delivery of the majority of injected porphyrin to the hepatocyte by hemopexin and lipoproteins. However, a large portion of the heme from senescent RBC is probably converted to bilirubin in the spleen (1). In the present study, the splenic HO activity that was not eliminated in the aqueous ZnPP-treated group and the saline-predosed L-ZnPPtreated group from Figure $1 B$ was evidently enough to allow those animals to keep pace with controls as far as total body $\mathrm{CO}$ production. Because the splenic $\mathrm{HO}$ activity of the liposomepretreated rats represented in Figure $1 B$ was totally eliminated, a significant decrease in total $\mathrm{CO}$ production was observed from $\mathrm{t}=8$ to $12 \mathrm{~h}$ relative to the other three groups. These results confirm the hypothesis of Landaw et al. (16) that delivery of adequate porphyrin to the spleen represents a major stumbling block to the optimum use of metalloporphyrin HO inhibitors as a therapy for neonatal jaundice.

We have demonstrated in a rodent model that active targeting of L-ZnPP to the spleen using reticuloendothelial blockade can increase $\mathrm{HO}$ inhibition there, with a corresponding decrease in $\mathrm{VeCO}$ when damaged $\mathrm{RBC}$ are injected as a hemolytic challenge. This targeting method, however, is cumbersome and might have adverse consequences, such as increased risk of infection in the high-risk neonate. Recent work using sterically stabilized liposomes with extended blood circulation times (Stealth liposomes, Liposome Technology, Inc., Menlo Park, CA) has shown that almost $50 \%$ of an injected dose of large liposomes can be 
delivered to the spleen, with most of the balance being delivered to the liver and less than $10 \%$ going to other tissues $(25,26)$. This phenomenon depends on the size of the liposome and the use of special lipids in the bilayer (27). The use of Stealth liposomes to encapsulate relatively lipid-soluble metalloporphyrin inhibitors of $\mathrm{HO}$ such as ZnPP might increase the potency of these drugs by allowing maximum delivery of inhibitor to heme-degrading tissues. At the same time, porphyrin would not be delivered to tissues where it might cause adverse reactions. We would predict large increases in the therapeutic efficacy of these drugs were this proved to be the case.

Acknowledgments. The authors thank Pamela Rodgers, Ph.D., Sinil Kim, M.D., and Dale Bull, M.D., Ph.D., for their assistance with this project.

\section{REFERENCES}

1. Maisels JM 1987 Neonatal jaundice. In: Avery GB (ed) Neonatology: Pathophysiology and Management of the Newborn. Lippincott, Philidelphia, pp 534-639

2. Landaw SA, Callahan EW, Schmid R 1970 Catabolism of heme in vivo: comparison of the simultaneous production of bilirubin and carbon monoxide. J Clin Invest 49:914-925

3. Johnson L 1991 Hyperbilirubinemia in the term infant: when to worry, when to treat. NY State J Med 91:483-489

4. Bratlid D 1991 Bilirubin toxicity: pathophysiology and assessment of risk factors. NY State J Med 91:489-492

5. Wennberg RP 1991 Cellular basis of bilirubin toxicity. NY State J Med 91:493496

6. Newman TB, Maisels JM 1990 Does hyperbilirubinemia damage the brain of healthy full-term infants? Clin Perinatol 17:331-358

7. Maines MD, Kappas A 1977 Enzymatic oxidation of cobalt protoporphyrin IX: observations on the mechanism of heme oxygenase action. Biochemistry $16: 419-423$

8. Drummond GS, Kappas A 1981 Prevention of neonatal hyperbilirubinemia by tin protoporphyrin IX, a potent competitive inhibitor of heme oxidation. Proc Natl Acad Sci USA 78:6466-6470

9. Qato MK, Maines MD 1985 Prevention of neonatal hyperbilirubinemia in non-human primates by $\mathrm{Zn}$-protoporphyrin. Biochem J 226:51-57

10. Hamori CJ, Vreman HJ, Rodgers PA, Stevenson DK 1989 Zinc protopor- phyrin inhibits $\mathrm{CO}$ production in rats. J Pediatr Gastroenterol Nutr 8:110115

11. Vreman HJ, Rodgers PA, Stevenson DK 1990 Zinc protoporphyrin administration for suppression of increased bilirubin production by iatrogenic hemolysis in rhesus neonates. J Pediatr 117:292-297

12. Kappas A, Drummond GS, Manola T, Petmezaki S, Valeas T 1988 Snprotoporphyrin use in the management of hyperbilirubinemia in term newborns with direct Coombs-positive ABO incompatibility. Pediatrics 81:485497

13. Stevenson DK, Rodgers PA, Vreman HJ 1989 The use of metalloporphyrins for the chemoprevention of neonatal jaundice. Am J Dis Child 143:353-356

14. Lasic DD 1992 Liposomes. Am Sci 80:20-31

15. Allen TM, Chonn A 1987 Large unilamellar liposomes with low uptake into the reticuloendothelial system. FEBS Lett 223:42-46

16. Landaw SA, Drummond GS, Kappas A 1989 Targeting of heme oxygenase inhibitors to the spleen markedly increases their ability to diminish bilirubin production. Pediatrics 84:1091-1096

17. Dave J, Patel HM 1986 Differentiation in hepatic and splenic phagocytic activity during reticuloendothelial blockade with cholesterol-free and cholesterol-rich liposomes. Biochim Biophys Acta 888:184-190

18. Richelli F, Jori G 1986 Distribution of porphyrins in the various compartments of unilamellar liposomes of dipalmitoyl-phosphatidylcholine as probed by fluorescence spectroscopy. Photochem Photobiol 44:151-157

19. Szoka F, Papahadjopoulos D 1980 Comparative properties and methods of preparation of lipid vesicles (liposomes). Annu Rev Biophys Bioeng 9:467508

20. Bowring CS, Glass HI, Lewis SM 1976 The rate of clearance by the spleen of heat-damaged erythrocytes. J Clin Pathol 29:852-854

21. Vreman HJ, Stevenson DK 1988 Heme oxygenase activity as measured by carbon monoxide production. Anal Biochem 168:31-38

22. Jori G, Tomio L, Reddi E, Rossi E, Zorat PL, Calzavara F 1983 Preferential delivery of liposome-incorporated porphyrins to neoplastic cells in tumourbearing rats. $\mathrm{Br} \mathrm{J}$ Cancer 48:307-309

23. Jori G, Beltramini M, Reddi E, Salvato B, Pagnan A, Ziron L, Tomio L. Tsanov T 1984 Evidence for a major role of plasma lipoproteins as hematoporphyrin carriers in vivo. Cancer Lett 24:291-297

24. Morgan WT, Alam J, Deaciuc V, Muster P, Tatum FM, Smith A 1988 Interaction of hemopexin with Sn-protoporphyrin IX, an inhibitor of heme oxygenase. J Biol Chem 263:8226-8231

25. Liu D, Mori A, Huang L 1991 Large liposomes containing ganglioside GM1 accumulate effectively in the spleen. Biochim Biophys Acta 1066:159-165

26. Klibanov AL, Maruyama K, Beckerleg AM, Torchilin VP, Huang L 1991 Activity of amphipathic poly(ethylene glycol) 5000 to prolong the circulation time of liposomes depends on the liposome size and is unfavorable for immunoliposome binding to target. Biochim Biophys Acta 1062:142-148

27. Woodle MC, Lasic DD 1992 Sterically stabilized liposomes. Biochim Biophys Acta 1113:171-199 